\title{
Economic aspects and the sustainability impact of the Athens 2004 Olympic Games
}

\author{
G. Tziralis, A. Tolis, I. Tatsiopoulos \& K. G. Aravossis \\ Sector of Industrial Management and Operational Research, \\ School of Mechanical Engineering, \\ National Technical University of Athens, Greece
}

\begin{abstract}
The terms of growth and environment are historically proven not to be compatible in principles, methods and targets. Economic investments are usually accompanied by actions that could not easily be characterized as environmentally friendly, while the strict application of environmental directives often results in halting development. Moreover, the tendency to constant economic growth is a desirable and inherent characteristic of human nature, which is apparently not to be changed in the near future. In this context, the pressing need for a bundle of approaches that could tie the objectives of economic growth and protection of environment had led to the field of sustainable development. The compatibility of each investment project with the principles of sustainable development should therefore be a matter of high priority. This text addresses the sustainability and the impact of the Olympic Games that were held in Athens in summer 2004. The Olympics comprise the biggest of events and their preparation extends to a scale capable of restructuring various spheres of economic activities. The sustainability issues that arise are therefore of major importance. This paper concerns the impact assessment of Olympic investments, in terms of properly selected and modified sustainable performance indicators focusing mainly on economy and environment.
\end{abstract}

Keywords: Olympic Games, sustainable development, impact assessment.

\section{Introduction}

\subsection{Growth versus environment}

Ecology and economy ought to push -in principle- in the same direction. The "eco" part of each word stands for the ultimate evidence, as it derives from the 
Greek word "home". In fully accordance, the protagonists of both claim to have common welfare as their primary goal.

Reality, however, is confirmed to be somehow different. The relationship between economic growth and the environment is, and may always remain, controversial. Considering the inherent to human nature tendency to constant economic development, the objectives of growth and environmental protection may arise as inconsistent. As Lucas [1] points out: "Once one starts to think about [economic growth], it is hard to think about anything else."

This relationship between economic growth and environment has received much attention in the recent decades. According to the early work of some social and physical scientists, growing economic activity (production and consumption) requires larger inputs of energy and material, and generates larger quantities of waste by-products $[2,3]$. At the other extreme, some researchers argue that the fastest road to environmental improvement is along the path of economic growth: with higher incomes comes increased demand for goods and services that are less material intensive, as well as demand for improved environmental quality that leads to the adoption of environmental protection measures [4]. As Beckerman [5] puts it, "The strong correlation between incomes, and the extent to which environmental protection measures are adopted, demonstrates that, in the longer run, the surest way to improve your environment is to become rich".

The newer 1990s literature focuses on the study of this link between economic growth and environmental quality. Panayotou [4] refers numerous researchers, such as Grossman and Kreuger [6] and Selden and Song [7], who have hypothesized that this relationship -between economic growth and environmental quality-, whether positive or negative, is not fixed along a country's development path; indeed it may change sign from positive to negative as a country reaches a level of income at which people demand and afford more efficient infrastructure and a cleaner environment. The implied inverted-U relationship between environmental degradation and economic growth came to be known as the "environmental Kuznets curve," by analogy with the income inequality relationship postulated by Kuznets.

\subsection{Sustainable development}

After all, no matter on what extent it is finally understood or remains a hot research topic, the relationship between economic development and environmental protection does exist. Considering the ambiguity of its nature, the need for a framework that secures the relationships' elements compatibility arises as of vital importance. Growth and environmental protection could and should be in harmony in principles, methods and targets; this harmony is called sustainable development.

In 1987, the World Commission on Environment and Development defined sustainable economic development as "development that meets the needs of the present without compromising the ability of future generations to meet their own needs" [8]. The United Nations responded thoroughly, yet in 1992, in this pressing need with the Agenda 21, an extended list of guiding principles and modus operandi, reflecting a global consensus and political commitment at the 
highest level on development and environment cooperation for the integration of environmental and development concerns [9].

The compatible to environmental protection framework for economic growth is therefore known and widely accepted. The matter that arises in a natural way regards the methods that may be used to assess the sustainability of economic development, whether it concerns the development of a region, enterprise or a project. According to the International Institute for Sustainable Development [10], it is necessary to identify the essential component systems and to define indicators that can provide essential and reliable information about the viability of each and of the total system. Such indicators, formed according to certain requirements $[10,11]$, are able to provide comprehensive information about the systems shaping sustainable development.

To abbreviate, the pressing need for harmonizing economic growth with environmentalism is assured only by the notion of sustainability, which should determine the boundaries for every development plan and could be assessed through properly defined indicators.

\subsection{The Olympics}

The Olympic Games comprise the biggest of events that a city can organize. The size of the Olympic event and the activities needed for the preparation and hosting of the Games are in a scale able to act as a catalyst for urban redevelopment, enabling changes which might normally take several decades to complete [12]. The growth and financial gigantism of the Games are today such that, for example, the overall impact of the Games of Sydney 2000 was to increase the whole Australian economic activity by $0.12 \%$ over a 12 -year period from 1994 [13].

As a direct result, the occurring investments and the reconstruction of the city pose a strong influence on the region's environment. The bundle of relevant issues is not covered sufficiently in the relevant Olympic bibliography, which is after all limited. However, the impact on the environment is considerably significant, in terms of raw materials used, energy consumption, water conservation, transport and contamination [14].

At long last, the size and extent of the economical and environmental issues that arise from hosting an Olympic event make the measurement of the sustainability of the project a subject of vital importance.

\subsection{Scope and contents}

The hereby study aims in recording, monitoring and assessing the sustainability impact of the Olympic Games of Athens 2004. The introductive section 1 is followed by an analytic description of the methodology selected and used for the Games' impact sustainable assessment in section 2. Section 3 portrays the economic dimension of the Games, while section 4 deals with environmental aspects. Section 5 summarises the paper's outcomes, while also suggests directions for further research. 


\section{The method}

The International Olympic Committee (IOC) has recently responded to the urging and tempting need of identifying and measuring the impact of the Games in terms of their sustainability by introducing the Olympic Games Global Impact (OGGI) project. The Académie Internationale des Sciences et Techniques du Sport (AISTS) of Lausanne studied and finally created -for the account of IOCa framework of analysis and a set of indicators for the identification of the sustainable impact of Olympics [15-18]. The fundamentals of this framework, which was created to capture in a consistent and comparable manner the impact of the Games, are described hereafter and in parallel illustrated in Figure 1.

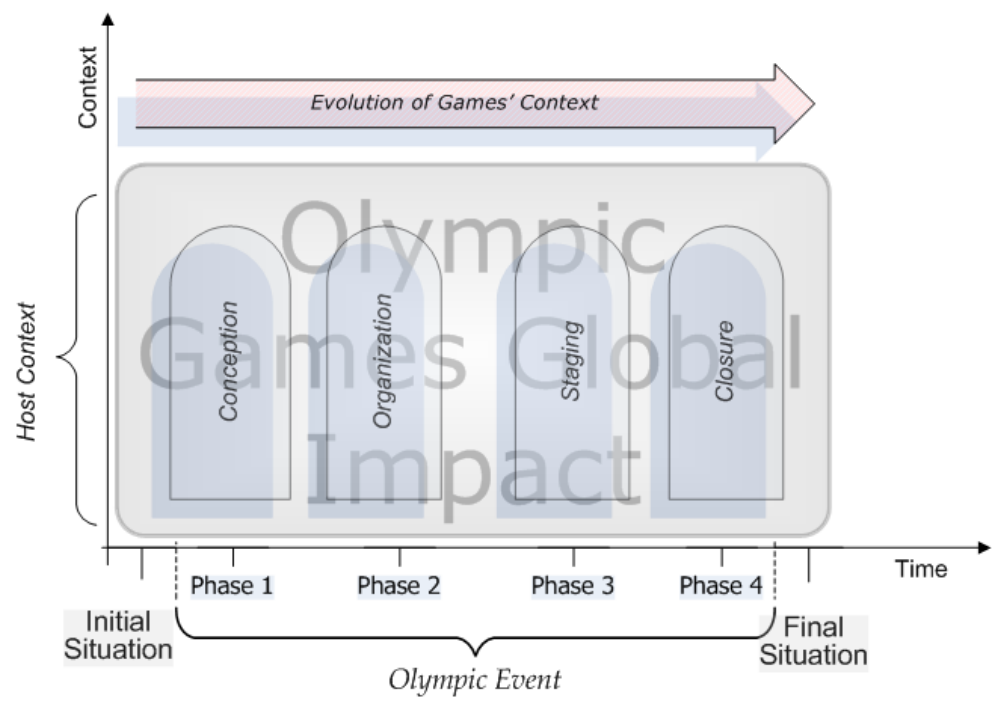

Figure 1: The Olympic Games Global Impact framework for the identification of the sustainable impact of Olympics.

As an essential consideration, the Games' impact is defined as the interrelation between the Olympic event and its context of realization. Adopting this dual view, two clusters of indicators are introduced, one for monitoring the event and another for the depiction of its context. The global intrinsic impact arises ultimately circularly, as an area in which the complex interrelationship between the event and its context takes place. The mapping of the area, with the appropriate spatial, temporal and details coloration, is selected to be incarnated by use of appropriately selected and modulated indicators.

The first degree of freedom which characterizes the set of indicators is space. The proposed framework considers three different geographical entities in regional, national and global level. The second degree of freedom regards time. As temporal boundaries are picked the official announcement of the city's candidacy (initial situation) and the completion of two years time after the 
staging of the Games (final situation), broken down in the phases of conception, organization, staging and closure.

The methodological framework outlines as relevant to the Olympic event two groups of activities. The first one, Olympic activities, includes the totality of activities that derive directly from the occurrence of the Olympic event, namely activities that were performed during the conception, development, use and postOlympic conversion of areas and facilities specific to the Games, such as sports areas and Olympic villages. The second one regards activities that aim at accomplishing the required existence of suited to the scale and complexity of the event infrastructure, such as transport networks.

The methodological framework results finally in a proposed set of 159 sustainable indicators and 1726 operational variables, congregating to the integrated assessment of the Olympic impact. For the needs of this study, a selected subset of these indicators, relevant and able to highlight the case of Athens, was worked out and the most updated data for them was collected, through an extensive search over the totality of relevant organizations and offices. The very most influential and illustrative outcomes out of these indicators, regarding the spheres of economy and environment, are analysed hereafter to document and determine the sustainable impact of the Olympic Games of 2004.

\section{Economic aspects of the Athens' Games}

\subsection{Economic size}

This section reports the main features of the economic dimension of Athens' Games. Adopting the approach of the OGGI framework, the economic sphere of the Games' impact is formed by both the event and its context of realization. The economic aspects of the Olympic event are covered in this subsection, while the next one discuss the evolution of the Games' economic context and marks out possible associations between the event and its context's evolution. The source for the raw data used for extracting the results referred to this subsection is the General Accounting Office of Greece.

The total expenditure of the Olympic Games of Athens 2004, both operating and capital, regarding the Olympic, as long as the context, activities was finally equal to 11.274 billion $€$. Only the $20.1 \%$ of this cost was covered by private funding, all the rest being public subsidy. According to the OGGI classification, the total amount of expenditure could be decomposed as follows. Capital expenditure on context activities was equal to 6.025 billion $€$, namely $53.4 \%$ of the total amount, whereas operating expenditure on context activities was 0.619 billion $€$. Regarding the Olympic activities, capital expenditure finally total to 2.248 billion $€$ and operating expenditure to 2.382 billion $€$. The extent of this spending could serve as an indisputable proof of the significant impact of the Games to the regional economy.

In addition, their catalyst effect, expressed as the ratio of expenditure on context activities divided by expenditure on Olympic activities, came finally up 
to 1.44 . The role of the public sector was of crucial importance, as public share covered $95.6 \%$ of the expenditures on context activities. The sustainability of the Games' impact could be further documented by the permanent nature of the facilities used for staging the Games. Out of the 1.975 billion $€$ spent for the renovation or construction of Olympic facilities, only $10.2 \%$ concerned temporal facilities.

\subsection{Impact to the city and country economics}

The previous subsection presented the size of the Olympic event. This one attempts to show evidence on associating the preparation and staging of the Games with the economic development of the hosting region, namely the prefecture of Attica, or even whole Greece.

The triggering effect of the Games, as long as the stimulation of numerous activities whose connection with the Games is difficult to identify, could be made clear through the parallel consideration of principal economic indicators of the hosting region and the whole country. Those that point to the most indicative views of impact are mentioned in the following.

The volume of labour force stands definitely among them. The country's labour force expanded from 4.526 millions of employees in 1998 to 4.844 millions, namely an increase of $7.0 \%$. In contrast, during the same period, the labour force in Attica prefecture ballooned from 1.596 to 1.784 millions of employees, an expansion of $11.8 \%$. This variation in extent could be ascribed to the Games, since the most part of the increase in Attica's labour force, namely $4.35 \%$, was monitored during the Games' year, as it is depicted in Figure 2. In other words, the Games were the major reason for attracting an extra amount of labour force in Athens, an amount which remained in the region after the staging of the event. The question that arises unsurprisingly regards the employment rate.

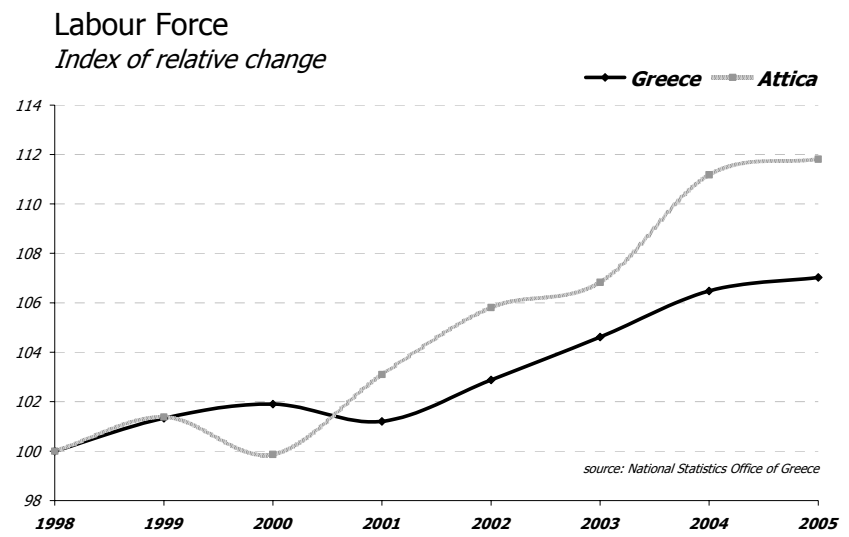

Figure 2: Index of relative change for labour force in Greece and Attica. 
The percentage of unemployed in both Greece and Attica prefecture were about $12 \%$ in 1999 . This percentage diminished successively in the following years till 2003. However, as figure 3 illustrates, the trend was more intense in Attica rather than in the whole country. As a result, the unemployment rate from 2003 to 2005 was $9 \%$ in the capital's region, while about $10 \%$ in national level. The Games was the major cause not only for greater inflow of employees, but also for a more efficient incorporation of these extra employees into Attica's economic system.

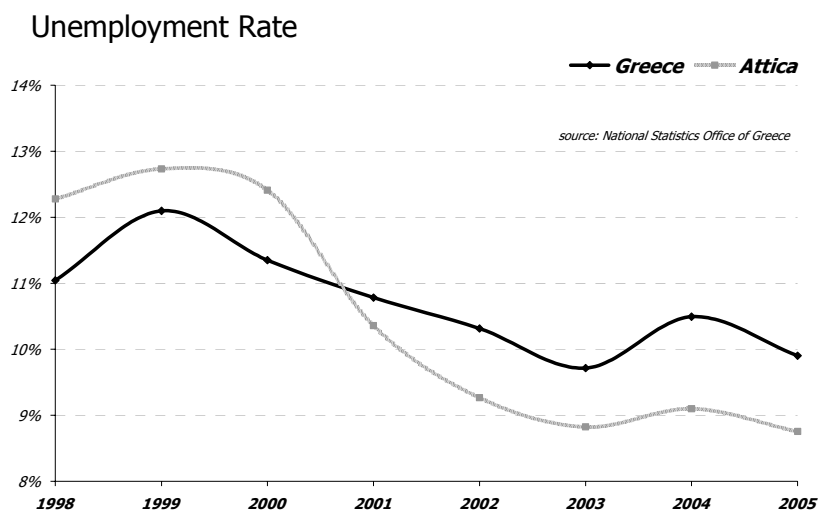

Figure 3: Unemployment rate in Greece and Attica.

The economic impact of the Olympic event could furthermore be confirmed in the evolution of specific sectors of national economy. For the period of 1998 to 2002, the total amount of full-time people employed in national economy was rather constant, nearly equal to 4.000 million people. On the contrary, the full time employees occupied in the relevant to the concept of the Games sectors of constructions and hotel / restaurants were significantly increased, as it is illustrated in Figure 4. In more details, the number of full time employees in the sector of constructions raised to $7.7 \%$ from 252 thousands people in 1996 to 298 thousands in 2002, while the number of people employed in hotels and restaurants was increased for $6.0 \%$, from 194 thousands people in 1996 to 232 in 2002.

It is finally apparent that the Olympic event fuelled economic development in a scale that makes the assessment of its environmental impact in terms of sustainability a serious need. The next section comes in answer to this requirement.

\section{Environmental impact: a sustainability assessment}

A project of the magnitude of the Athens' Games, as this was evidenced in economic terms in the previous paragraphs, is expected to have a similar wide- 
ranging effect on various environmental topics. The analysis performed, adopting the guidelines of the OGGI methodology, indicated a varied range of significance among the various environmental aspects that emerged during the organization and staging phases. The indicators studied regard primarily the Games' context, and they are implemented in a way that their evolution is able to grasp significant changes. These changes could afterwards be assigned to the Games' impact, following some empirical qualitative criteria, such as the relevance of their time of occurrence with the event. The most influential out of these indicators are presented afterwards, while clustered appropriately into sets that portray the Games' generic sustainability impact.

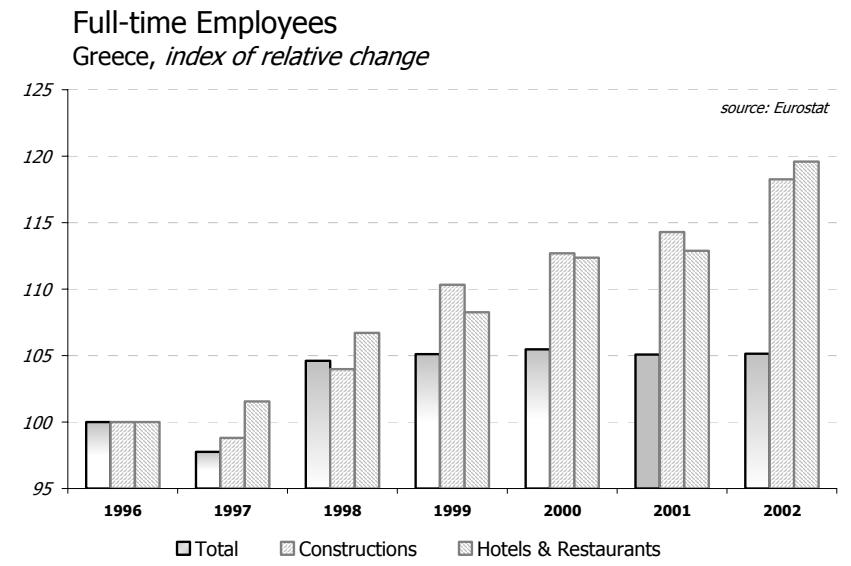

Figure 4: Index of relative change of full- time employees in Greece.

\subsection{Transport networks}

During the organization phase of the Games, a substantial recreation of the public transport networks was carried out in the city of Athens. At the beginning of this ambitious program in 1996, an obsolete metro was the only railway system in the Attica region, while the use of buses or private cars was almost unaffordable, as the average duration of stationary traffic was 6 hours per day. After all the often belated and repeatedly over budgeted works, a rather new Athens public transport system, described right below, was ready for serving both the Games and the citizens of Athens.

The basic component of this system is the brand-new underground railway that connects more than 20 municipalities of Attica; its operational distance is currently greater than $160 \mathrm{Km}$ and it is planned to exceed $250 \mathrm{~km}$, while the construction of new lines has already begun. The also brand-new suburban railway is another essential part of the transport system. The railway links the also new- Athens International Airport Eleftherios Venizelos with the city's centre and with 3 another adjacent cities. Its operational distance extended in 2005 to $120 \mathrm{~km}$. Furthermore, a brand-new tram railway was created, which 
connects the centre with the southern suburbs of Athens and provides a beautiful route nearby the city's coast. In total, as depicted in Figure 5, the underground railway system has been increased by $174 \%$, while the railway system and bus lanes of more than $90 \mathrm{~km}$ of operational distance had never been implemented before. The reengineering of the public transport system could easily be assigned to the Games' impact, as the event was the motive, as well as the date of completion, for the totality of the relevant works. The improved public transport system is moreover a component of the city's Olympic legacy that testifies the sustainability of the Games, as this arises through the potential extended use of public means of transportation and the subsequent improvement of quality of life.

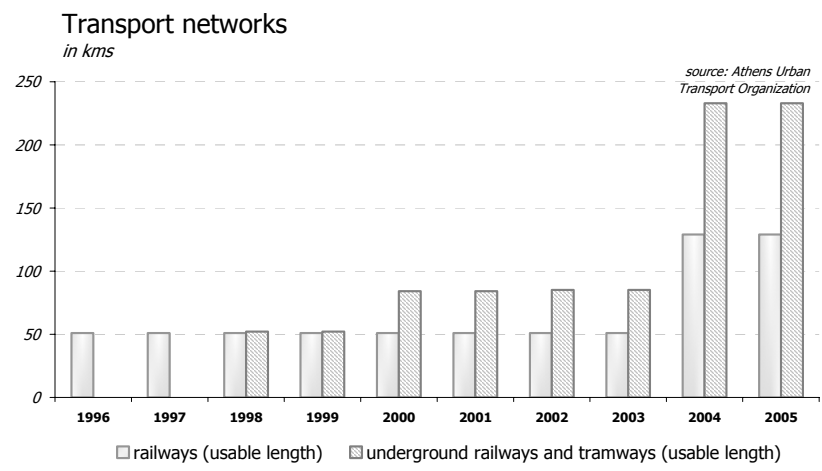

Figure 5: Usable length of transport networks.

Another major impact on the transport networks regards the renovation and expansion of the city's road network. The brand-new Attiki Odos (means Attica Road) offered $67 \mathrm{~km}$ of motorway through 30 municipalities of Attica prefecture and serves daily more than 250.000 cars. This motorway has recently been characterized as the safest motorway of Europe due to its lowest accident rates. Moreover, almost $130 \mathrm{~km}$ of the existing highway network of the prefecture has been renewed or repaired and more than 100 uneven-underpass complexes accompanied by bridges and tunnels have been added. The improved roadnetwork crosses 50 municipalities of the prefecture and serves almost $100 \%$ of the 5 millions of Attica's population. The significance of the new or improved road network could be confirmed by Figure 6. The operation of Attiki Odos in 2000 resulted in 2 less hours of stationary traffic per day on average, a result that further serves the sustainability of the Olympic impact.

\subsection{Pollution}

The question that arises logically from the great improvement of the transport networks concerns primarily the monitoring of effect on life quality not only in terms of traffic but also in terms of atmospheric pollution as well. This is analyzed in the next paragraph. 


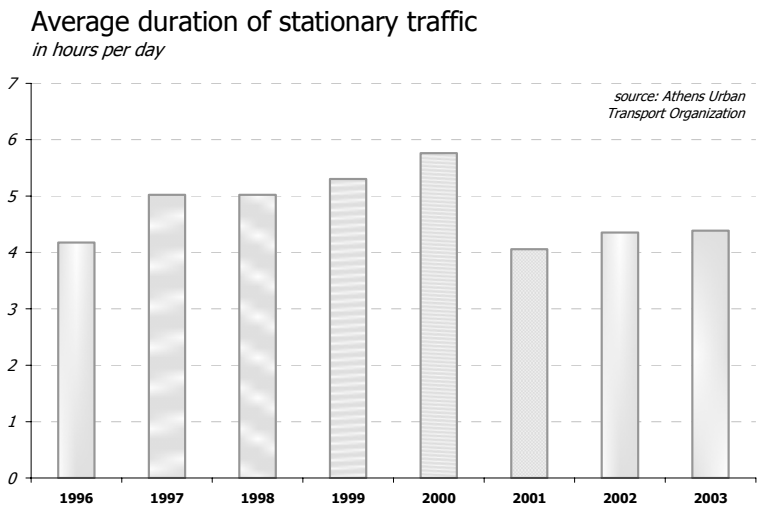

Figure 6: Daily average duration of stationary traffic in the city of Athens.

The time-series of the main atmospheric pollutants concentration, namely $\mathrm{O}_{3}$, $\mathrm{CO}_{2}, \mathrm{CO}, \mathrm{NO}_{2}$ and $\mathrm{SO}_{2}$, characterized by the common feature of local maximum around year 2000. Since then a moderate decrease - below the limits established by the European Union- describes the time evolution of these pollutants. The improvements of the road network, mainly the operation of Attiki Odos, and the opening of an extension to the underground railway that completed in this period may serve as a reliable cause.

It has to be noted, however, that the TSP pollutant, which corresponds to tiny "flying" solid microparts, has been increased since 2000. This increase can be attributed to the peak phase of public works, especially those related with new roads, as well as sport-facilities and infrastructure. After the year 2003 the TSP measurements indicated a slow return to the normal levels.

Regarding the raw material consumption and usage, it has to be reported that the domestic production and the imports of the typical raw materials (metals, wood, cement related materials) were maximised during the high-demanding period between the years 2000 and 2003 (Figure 7).

\subsection{Other areas}

The Olympics served moreover as the major or minor cause for improvements in urban planning and development. In the totality of the Olympic cities, including Thessaloniki, Patrai, Volos and Herakleion, a wide revitalization program has been carried out. Especially Athens has been engaged in a tight refreshment schedule during which ancient sites became easier to access and museums were renewed. The most important out of these works was the restoration of the ancient forum around the Acropolis.

Furthermore, the Games were a reason to increase the number and extent of protected areas and natural sites, in an effort to safeguard the forests and enforce the ecological sensitization and awareness of the population. In the years between 1996 and 2004, the surface of protected areas has been increased more than $6 \%$, especially in the wider areas of great ecological importance and biodiversity. 


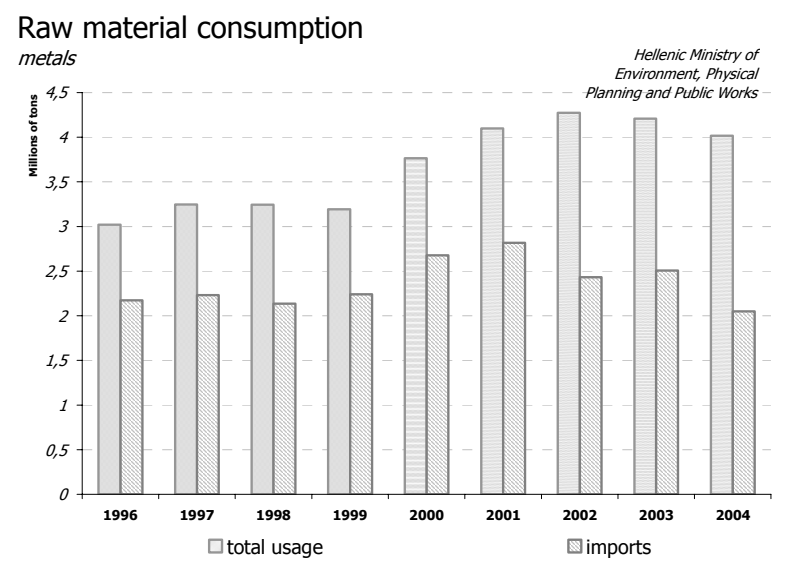

Figure 7: Raw material consumption in Greece.

\section{Conclusions}

The enormous size of the modern Olympics and the controversial relationship between economic growth and environmental protection give rise to the pressing need of testing the compatibility of the Games with the principles and directions of sustainable development. This paper is the first attempt to assess the sustainable impact of an Olympic event, implementing the methodology shaped by the International Olympic Committee, namely the guidelines of the Olympic Global Impact Project. The text addresses the sustainable impact of the Olympic Games of Athens 2004, focusing mainly on economic and environmental aspects. The principal findings could be summarized as follows.

The most part of the total 11.274 billion $€$ spent on the Olympic project regard activities on the context of the Olympic event, that is not directly related to it, but needed for providing the infrastructures for staging it. This strong catalyst effect of Games was mainly funded by public subsidies. The impact of the event on the regional economy was also significant. During the organization phase, the volume of labour force presented a greater increase in the Attica prefecture than in national scale, while the unemployment rate presented a higher decrease. The Games also resulted in the growth of the sectors of constructions and hotels / restaurants in a scale larger than the overall growth of the national economy.

The sustainable impact of the Games' event in the sphere of environment was also of great significance. Especially on the issue of transport networks, the Games served as a strict pressure factor that finally resulted in a massive reengineering of the public transport system and the road network. The underground railway network grew by a factor of 1.74, a new railway and bus lanes network was constructed and $200 \mathrm{~km}$ of rather new or upgraded motorways effected in a significant decrease of stationary traffic. The resulting decrease of atmospheric pollutants after the year of 2000, despite the high consumption of raw materials, is a further documentation of the sustainable impact of the Games. 
This consideration of the Olympic impact in terms of sustainability is a rather novel but promising research area. The constant growth of the Games' scale, as well as the increased concerns on sustainability, supports this belief. The paper could serve as a starting point for the relevant literature, but also as a reference for evaluating and comparing similar in size and nature events. The assessment could be extended in the areas of tourism or social impacts, while the modification of the framework used towards a more rigid but practicable one are directions that further research could be focused on.

\section{References}

[1] Lucas, R.E., On the mechanics of economic development, Journal of Monetary Economics, 22, pp. 3-42, 1988.

[2] Georgescu-Roegen, N., The Entropy Law and the Economic Process, Cambridge, Harvard University Press, 1971.

[3] Meadows, D.H., Meadows, D.L., Randers, J. and Behrens, W.W., The Limits to Growth, London, Earth Island Limited, 1972.

[4] Panayotou, T., Economic growth and the environment, CID Working Paper No. 56, Harvard University, 2000.

[5] Beckerman, W., Economic Growth and the Environment: Whose Growth? Whose Environment? World Development, 20, pp. 481-496, 1992.

[6] Grossman, G., and Kreuger, A., Economic Growth and the Environment, Quarterly Journal of Economics, 110 (2), pp. 353-377, 1995.

[7] Selden, T.M., and Song, D., Environmental Quality and Development: Is there a Kuznets Curve for Air Pollution Emissions? Journal of Environmental Economics and Management, 27,pp. 147-162, 1994.

[8] World Commission on Environment and Development (WCED), Our common future: The Brundtland report, Oxford: Oxford University Press, 1987.

[9] United Nations, Agenda21, United Nations Conference on Environment \& Development, Rio de Janeiro, Brazil, 1992.

[10] Bossel, H., Indicators for Sustainable Development: Theory, Method, Applications, International Institute for Sustainable Development Report, Manitoba, Canada, 1999.

[11] United Nations Commission on Sustainable Development, Indicators of Sustainable Development, Guidelines and Methodologies, Third Session Report, 1995.

[12] Preuss H., The Economics of Staging the Olympics, Edward Elgar Publishing, UK, 2004.

[13] Arthur Andersen, Economic Impact Study of the Sydney 2000 Olympic Games, Executive Summary, 1999.

[14] Greenpeace, How green the Games, Sydney, Australia, 2000.

[15] Griethuysen, P., A general framework for the identification of the global impact of major sports events, in Proceedings of the SEMOS, pp. 97-103, Lausanne, 2001. 
[16] Hug, P.A., Sports event assessment, Proceedings of the SEMOS, pp. 104109, Lausanne, 2001.

[17] Griethuysen, P. and Hug, P.A., Project OGGI Olympic Games Global Impact. Cadre d'analyse pour l'identification de l'impact global des Jeux Olympiques, Lausanne, 2001.

[18] Griethuysen, P. and Hug, P.A., Project OGGI Olympic Games Global Impact. Fiches techniques, Lausanne, 2001. 